NASA Technical Memorandum 106444

$$
\begin{aligned}
& \text { NASA-TM- } 106444 \\
& \text { Conf }-940101-34
\end{aligned}
$$

\title{
Preliminary SP-100/Stirling Heat Exchanger Designs
}

Paul Schmitz and Leonard Tower

Sverdrup Technology, Inc.

Lewis Research Center Group

Brook Park, Ohio

Ronald Dawson

Aerospace Design and Fabrication Inc.

Brook Park, Ohio

and

Brian Blue and Pat Dunn

National Aeronautics and Space Administration

Lewis Research Center

Cleveland, Ohio

Prepared for the

Eleventh Symposium on Space Nuclear Power and Propulsion

cosponsored by the Institute for Space Nuclear Studies and American Nuclear Society Albuquerque, New Mexico, January 10-14, 1994 


\section{DISCLAIMER}

This report was prepared as an account of work sponsored by an agency of the United States Government. Neither the United States Government nor any agency Thereof, nor any of their employees, makes any warranty, express or implied, or assumes any legal liability or responsibility for the accuracy, completeness, or usefulness of any information, apparatus, product, or process disclosed, or represents that its use would not infringe privately owned rights. Reference herein to any specific commercial product, process, or service by trade name, trademark, manufacturer, or otherwise does not necessarily constitute or imply its endorsement, recommendation, or favoring by the United States Government or any agency thereof. The views and opinions of authors expressed herein do not necessarily state or reflect those of the United States Government or any agency thereof. 


\section{DISCLAIMER}

Portions of this document may be illegible in electronic image products. Images are produced from the best available original document. 


\section{Preliminary SP-100/Stirling Heat Exchanger Designs}

\author{
Paul Schmitz, Leonard Tower \\ Sverdrup Technology \\ Incorporated \\ Lewis Research Center Group \\ Brook Park, OH 44142
}

(216) 433-6174

\author{
Ronald Dawson \\ Aerospace Design and \\ Fabrication Inc. \\ 3003 Aerospace Parkway \\ Brook Park, OH 44142
}

(216) 433-3804

\author{
Brian Blue, Pat Dunn \\ Engineering Directorate \\ NASA Lewis Research Center \\ 21000 Brookpark Road \\ Cleveland, $\mathrm{OH} 44135$
}

(216) 433-3801

\section{ABSTRACT}

Analytic modeling of several heat exchanger concepts to couple the SP-100 nuclear reactor primary lithium loop and the Space Stirling Power Convertor(SSPC)was performed. Four $25 \mathrm{kWe}$ SSPC's are used to produce the required $100 \mathrm{~kW}$ of electrical power. This design work focused on the interface between a single SSPC and the primary lithium loop. Manifolding to separate and collect the four channel flow was not modeled. This work modeled two separate types of heat exchanger interfaces (conductive coupling and radiative coupling) to explore their relative advantages and disadvantages. The minimum mass design of the conductively coupled concepts was $18 \mathrm{~kg}$ or $0.73 \mathrm{~kg} / \mathrm{kWe}$ for a single $25 \mathrm{kWe}$ convertor. The minimum mass radiatively coupled concept was $41 \mathrm{~kg}$ or $1.64 \mathrm{~kg} / \mathrm{kWe}$. The direct conduction heat exchanger provides a lighter weight system because of its ability to operate the Stirling convertor evaporator at higher heat fluxes than those attainable by the radiatively coupled systems. Additionally the conductively coupled concepts had relatively small volumes and provide potentially simpler assembly. Their disadvantages were the tight tolerances and material joining problems associated with this refractory to superalloy interface. The advantages of the radiatively coupled designs were the minimal material interface problems.

\section{INTRODUCTION}

During 1992 several concepts to integrate the SP-100 primary lithium loop to a Stirling convertor were explored. The SP-100 is a joint NASA, Department of Energy and Department of Defense space nuclear reactor system which passes lithium reactor coolant directly over the hot shoe of the multicouple thermoelectric power convertors. Stirling convertors have been proposed as a high efficiency power conversion alternative to the thermoelectrics. Originally a refractory alloy $(1300 \mathrm{~K})$ Stirling convertor was proposed for this purpose. Because of funding limitations the Stirling convertor development ended with a superalloy (Inconel 718) convertor. With a material substitution of Udimet 720 a 7 year convertor life could be achieved at a convertor hot end temperature of $1050 \mathrm{~K}$. The Inconel convertor called the Space Stirling Power Convertor (SSPC) is being developed for the Civil Space Technology Initiative (CSTI) at NASA Lewis Research Center for this purpose. (Dudenhoefer 1992) The SSPC is designed to produce $25 \mathrm{~kW}$ of electrical power with an efficiency of $25 \%$ at a temperature ratio of 2.0 and a specific mass of $6.0 \mathrm{~kg} / \mathrm{kWe}$.

This study focused on two separate types of heat exchangers to interface the SP-100 and the SSPC. The concepts are differentiated by the method in which the SP-100 loop and the Stirling hot end heat pipe condenser (called the Starfish Heater Head) are connected. The first group of designs couple the hot primary lithium loop of the SP-100 to the Stirling convertor by radiating between the two systems. The second group couples the systems by a conductive interface similar to the design used for the multicouple thermoelectrics. Common to both are a lithium loop with refractory metal piping on the SP-100 side and a sodium filled, superalloy heat pipe on the Stirling convertor side. This heat pipe transfers heat to the working gas in the convertor. Several advantages and disadvantages for both ideas exist. The primary advantage of the radiatively coupled designs is that the separation of the heat source and the convertor prevented material compatibility problems. The primary problem with the radiatively coupled design is that the maximum heat flux achievable between the $1300 \mathrm{~K}$ lithium loop and the $1050 \mathrm{~K}$ Stirling convertor was about $8 \mathrm{~W} / \mathrm{cm}^{2}$ while the evaporator of the sodium heat pipe has a heat flux limit of $40 \mathrm{~W} / \mathrm{cm}^{2}$. This is due to the heat transfer limitations of Boltzman's $\mathrm{T}^{4}$ radiative heat transfer law for the temperatures being considered.

A conductively coupled liquid lithium to Starfish heater head heat exchanger was explored to maximize heat transfer into the Stirling convertor. Although the conductively coupled designs have the potential of much greater heat fluxes, no single material is compatible with both liquid sodium on the convertor side and liquid lithium on the 
SP-100 side. Furthermore, heat transfer analysis shows that a heat flux in the neighborhood of 160 watts $/ \mathrm{cm}^{2} \propto c c u r s$ when the hot primary lithium flows directly over an $1 / 32$ inch Inconel heat pipe operating at $1050 \mathrm{~K}$. This is much greater than the allowed $40 \mathrm{watt} / \mathrm{cm}^{2}$ and must be compensated for in the design.

This study developed two heat exchanger concepts for coupling the SP-100 to the SSPC. Calculations are made to predict heat flows, structural requirements, and thermal characteristics of the designs. Volume and mass estimates are made of the components for each heat exchanger.

\section{REOUREMENTS}

Any of the heat exchanger designs proposed allow the Stirling convertor to be inserted directly into the flow path currently occupied by the thermoelectrics in the primary loop of the SP-100. Therefore, during the design work the heat exchanger configurations were made to match, as closely as possible, the current thermoelectric SP-100 thermohydralic primary loop characteristics. These requirements set parameters such as temperature drop (75 K), reactor materials $(\mathrm{Nb}-1 \% \mathrm{Zr})$, and pressure loss $(-2.0 \mathrm{psi})$.

\section{RADIATVELY COUPLED DESIGN}

Analysis shows that radiatively coupled designs allow a heat flux of 8 watt $/ \mathrm{cm}^{2}$ into the evaporator of the Starfish while having the potential to operate at 40 watts $/ \mathrm{cm}^{2}$. This decrease in heat flux could have an adverse affect on both mass and volume of any of the radiatively coupled concepts considered. The primary advantage to the radiatively coupled design was that the separation of the heat source and the convertor prevent material compatibility problems.

Several radiative concepts were developed in this design study. Of the designs considered the toroidal concept was found to be the lightest and easiest to manufacture. This paper will elaborate only on the toroidal concept. This concept (See Figure 1 and 2), uses a single radiator panel made of $\mathrm{Nb}-1 \% \mathrm{Zr}$ which is wrapped around the evaporator torus. The primary loop lithium flows through an inlet manifold that distributes the flow to $\mathrm{Nb}-1 \% \mathrm{Zr}$ tubes embedded in the radiator panel which conducts the heat to the panel fins. The tubes are formed by the PLATECOIL fabrication process in the $\mathrm{Nb}-1 \% \mathrm{Zr}$ radiator plate (Trantor Inc. 1990). In turn these fins radiate to the Stirling convertor's heat pipe evaporators. The lithium is collected in an exit manifold and returned to the reactor.

The evaporated sodium in the Starfish flows radially in to the convertor to the Starfish heater head and is condensed. The sodium is then pumped back to the evaporator through the capillary pumping action of arteries and then distributed to the evaporator through wire mesh wicking. Each sodium evaporator feeds half of the $25 \mathrm{kWe}$ SSPC convertor.

\section{Thermal Analvsis}

The SSPC helium gas temperature was required to have a hot side inner wall temperature of $1050 \mathrm{~K}$. Calculations showed that a $16 \mathrm{~K}$ temperature drop can be expected from the inner wall of the Stirling convertor gas passages through the heat pipe to the outer wall of the evaporator. This required that the evaporator of the heat pipe operate at $1066 \mathrm{~K}$. From the $1312 \mathrm{~K}$ average lithium temperature and the required $1066 \mathrm{~K}$ heat pipe evaporator temperature a total thermal resistance of $2.46 \mathrm{~K} / \mathrm{kW}$ is calculated(Lubarsky 1955).

An emissivity of 0.9 was used on both the super alloy Stirling convertor surface and the $\mathrm{Nb}-1 \% \mathrm{Zr}$ side. These emissivities are the results of arc texturing research performed at NASA Lewis Research Center under the CSTI(Banks 1988). These values lead to a theoretical minimum required radiator area of $1.28 \mathrm{~m}^{2}$ to transfer 100 $\mathrm{kWth}$ between surfaces at an average of $1312 \mathrm{~K}$ on the lithium side and $1066 \mathrm{~K}$ on the super alloy side. All four concepts use a parallel tube configuration for the reactor side high temperature radiator panels. Each radiator panel lithium flow passage has an inner diameter of $5.08 \times 10^{-3}$ meters. This results in Reynolds numbers of approximately 10,000 and a total convective resistance of $1 \%$ of the allowable. Using a $\mathrm{Nb}-1 \% \mathrm{Zr}$ radiator panel thickness of $1.27 \times 10^{-3}$ meters and a total of $20,6.35 \times 10^{-3}$ meters diameter tubes, the total conductive resistance is estimated to be $10 \%$ of the allowable. With the addition of the radiation resistance a radiator area of $1.5 \mathrm{~m}^{2}$ is required. This is only $17 \%$ higher than the ideal radiator area of $1.28 \mathrm{~m}^{2}$. 


\section{Multi-Foil Insulation}

Thermal insulation was needed to reduce the amount of heat lost into the convertor and to control the environment of the power system. Molybdenum Multi-Foil insulation was chosen because of its' light weight and excellent insulation properties when used in vacuum. Estimates of heat loss through the insulation are made based on the temperature of the inner and outer layers of the Multi-Foil and the heat flux through the insulation(Wortham 1988). A 5\% heat loss set the required number of layers of insulation. The toroidal heat exchanger required 20 layers of Multi-Foil.

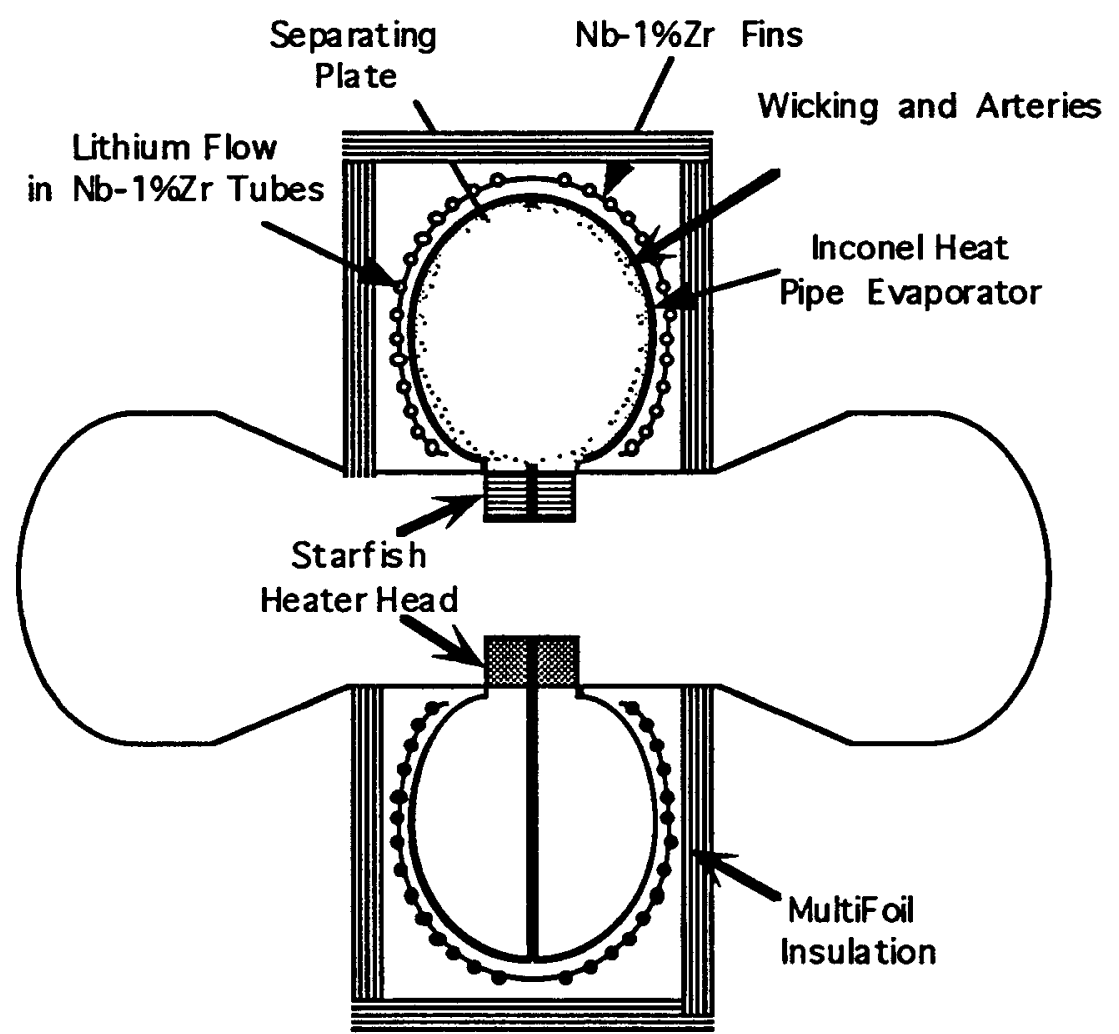

\section{Stress Analysis}

FIGURE 1. Cross Section of SSPC Radiatively Coupled Heat Exchanger.

Calculations were made to evaluate required material thicknesses for the heat pipe in each of the concepts. The material used for the heat pipe is Inconel 617 that has an allowable stress of $62 \times 10^{6}$ Pascal's for 60,000 hrs of life. The maximum temperature this material is subjected to is $1066 \mathrm{~K}$. To achieve the necessary area for heat transfer a 0.308 meter torus was required. A burst disk was placed in the heat pipe wall to insure that if a high pressure helium leak occurs in the Stirling convertor/heat pipe interface the possibility of insertion of helium into the primary reactor loop is reduced. The burst disk was designed to operate at $1.48 \times 10^{5} \mathrm{Pascal}$ 's for the lifetime of the system without bursting. The internal pressure of the convertor is $1.55 \times 10^{7}$ Pascal's . The burst disk was sized to fail at $1.48 \times 10^{6}$ Pascal's. This lead to a $2.54 \times 10^{-2}$ meter diameter disk. Mass results of the analysis are given in Table 1 . Concept 3 was chosen as the easiest to fabricate while also providing a lightweight interface between the SP-100 and the CTPC.

\section{Elow Channel Sizing}

Pressure drop calculations were made based on flow channel equivalent lengths around the reactor side of the liquid metal heat exchanger. Pressure drops included those in the inlet and outlet manifolds and the PLATECOIL heat exchangers. The lithium flow tubes were sized to give reasonably low flow velocities $(<3 \mathrm{~m} / \mathrm{s})$ to minimize pressure losses while always maintaining a turbulent flow $(\operatorname{Re}>4000)$ to enhance heat transfer. The wall thickness of 
the tubes was set to accommodate the 0.151 Pascal's pressure of the lithium loop. The selection of $\mathrm{Nb}-1 \% \mathrm{Zr}$ as the lithium side material led to initial sizing of the tubing at $6.35 \times 10^{-3}$ meters in diameter and $6.35 \times 10^{-4}$ meters thick.

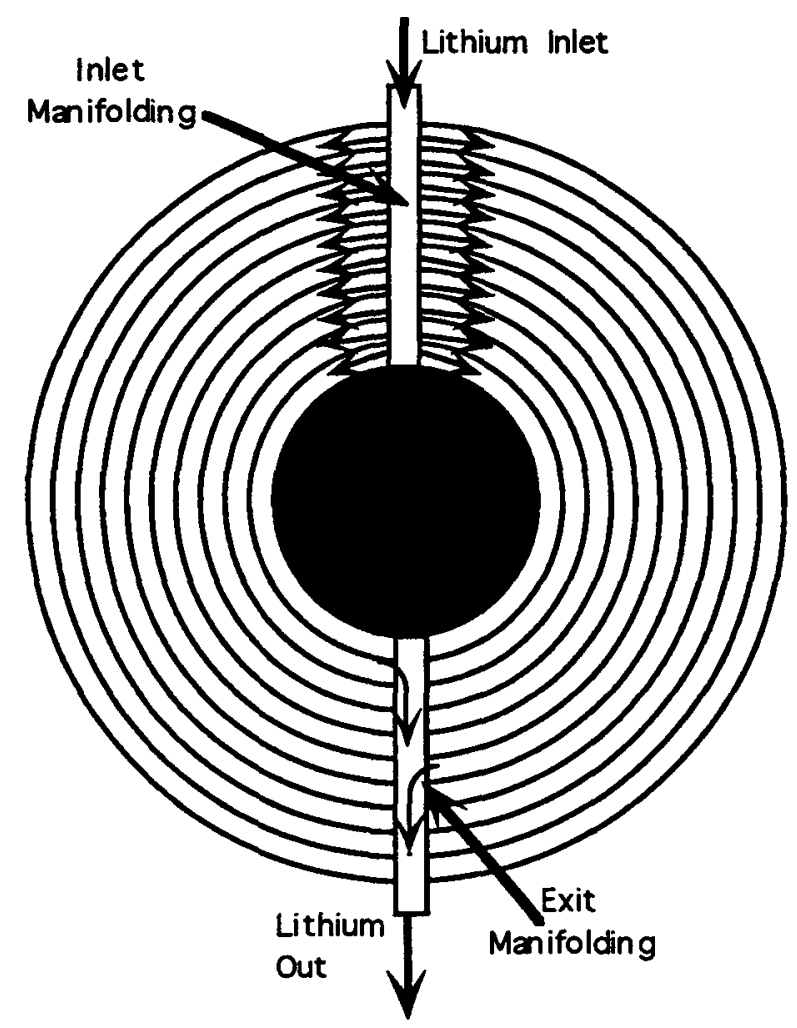

FIGURE 2. Flow Path of Lithium in Radiatively Coupled Heat Exchanger

\section{Heat Pipe}

A conservative 100 mesh stainless steel wire $\left(0.01\right.$ inch $\left.^{-1}\right)$ was used for the wicking and arteries in all the concepts. This selection was based on preliminary results from wick erosion tests currently under test through a Lewis Research Center program. These results suggest that, without a coating, sodium erosion of the nickel in the stainless steel wicking is significant in thin wire screens. One hundred mesh wire was selected as the wicking size of choice because tests indicate this wire size will survive the seven year life requirement of the system. Because higher mesh sizes (smaller interwire spacing) provide increased capillary pumping ability it was desirable to use as fine a mesh wick as possible. Finer mesh sizes were considered and as more data becomes available this design choice may change. The 100 mesh wicking provides a total pumping height of about 0.254 meter's in a $1 g$ environment. This was important because of ground testing considerations.

Table 1.

Weight Comparisons (Weight (kg) / Thickness (Meters))

$\begin{array}{lcccccc} & \text { Disks } & \text { Radiator Fins } & \text { Insulation } & \text { Manifolds } & \text { Total } & \\ \text { Single Torus } & 13.4 & 18.09 & 11.41 & 1.68 & 44 & \mathrm{~kg} \\ & 1.0 \mathrm{E}-3 & 1.27 \mathrm{E}-03 & 5.08 \mathrm{E}-04 & 8.9 \mathrm{E}-04 & & \end{array}$

In each of the designs wicking and artery attachment became a significant factor in the designs. Attachment methods for the wick and artery along. with a relative ease of assembly influenced the choice of heat exchanger type. The single torus concept provided the easiest attachment of wicks and arteries. Because of the relatively large size of the torus in this concept a center separating plate was required between the two heat pipe sections to reduce the pumping height of the sodium when the system is ground tested. This effectively reduces the pumping height in half. In all the concepts no additional mass penalty is included because of the wicking attachment. 


\section{CONDUCTIVELY COUPLED HEAT EXCHANGER}

A conductively coupled liquid lithium to Starfish heater head heat exchanger was modeled to increase heat transfer into the Stirling convertor and potentially reduce the heat exchanger mass. Although directly coupled designs have the potential of much greater heat fluxes no single material is compatible with liquid sodium on the convertor side and liquid lithium on the SP-100 side. Furthermore, a heat transfer analysis showed that a heat flux of 160 watts $/ \mathrm{cm}^{2}$ occurs when the hot primary lithium is passed directly over the evaporator of the Starfish heater head. This was much greater than the allowed 40 watt $/ \mathrm{cm}^{2}$ and must be compensated for in the design. A unique solution to these problems is developed. Figure's 3,4 , and 5 show the design in detail. Heat is transferred to each half of the SSPC separately by splitting the lithium flow in a manifold. Five cylindrical heat pipes evaporators (10 total for the dual opposed convertor) on each side of the convertor are used to input heat to the heat pipe. The lithium is run in series through each of the five cylindrical heat pipes. Because the total temperature drop through the heat exchanger is $75 \mathrm{~K}$, each heat pipe experiences a temperature drop of $15 \mathrm{~K}$.

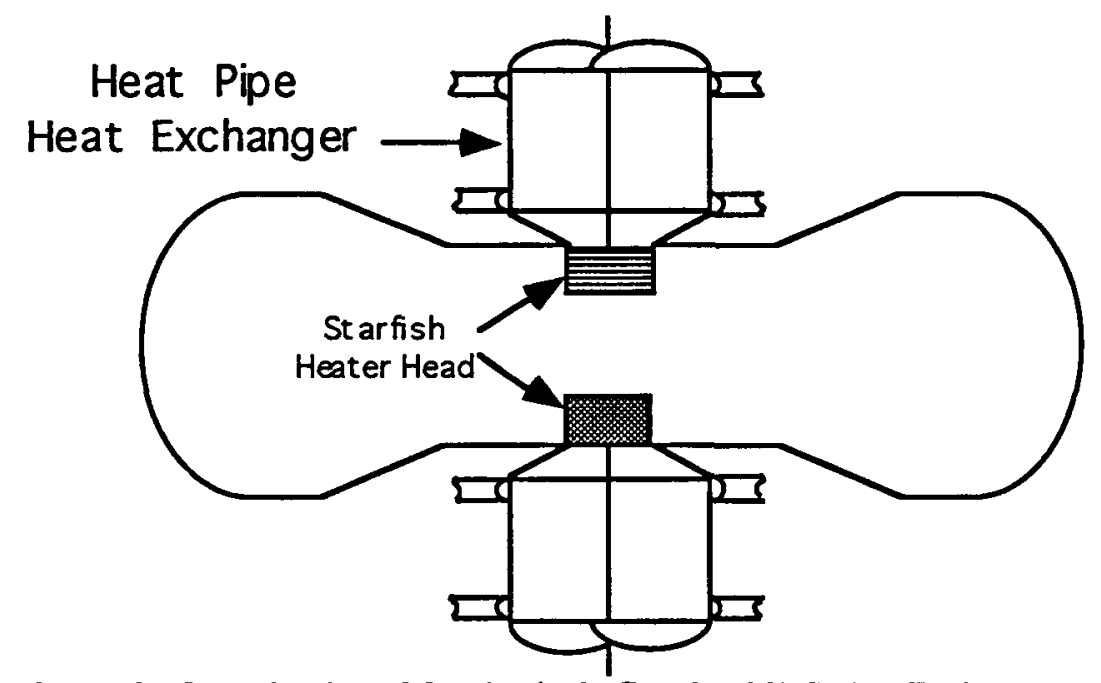

FIGURE 3. Cross Section of Conductively Coupled SSPC Heat Exchanger.

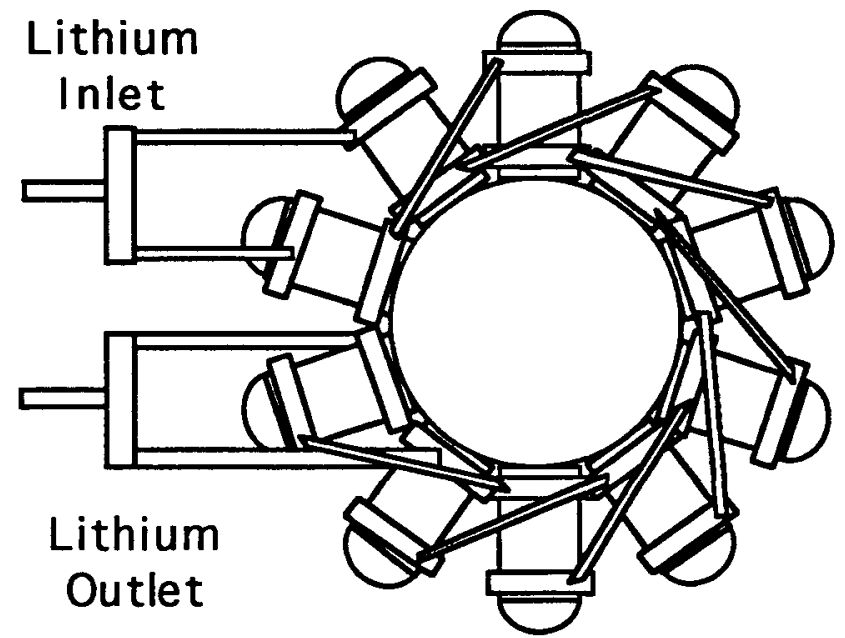

FIGURE 4. Lithium Flow Channels for Heat Exchanger.

Each of the proposed heat exchanger heat pipe evaporators consists of two basic components. The first is a Inconel 617 inner tube which acts as the evaporator section of the sodium Starfish heat pipe. To limit the heat flux into the heat pipes a thermal barrier coating (TBC) is applied to the outside of each of the Inconel tubes with a NiCrAly bond coat. Zirconia is used as the TBC because of its poor thermal conductivity and well-understood 
material characteristics. This type of TBC has been used successfully for years on commercial jet engine turbines at much higher temperatures than will be seen in this application. Wicks and arteries are attached to the inside wall of

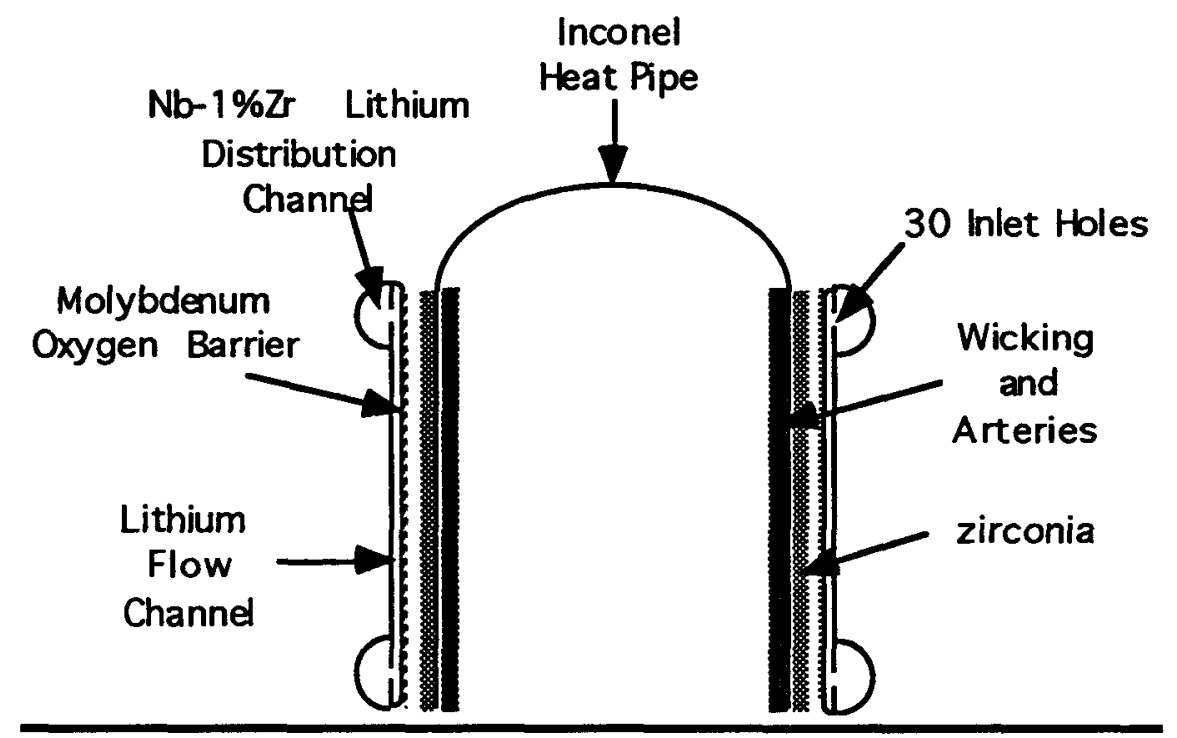

FIGURE 5. Detailed Cross-Section of Heat Pipe Evaporator.

the tube to distribute the sodium working fluid to the evaporative surface. The arteries run from the outside ends of the pipe to the roots of the fins in the Starfish to collect the condensed sodium and return it to the evaporator.

The second component is the outer $\mathrm{Nb}-1 \% \mathrm{Zr}$ shell which slip fits over the Inconel tube. This shell consists of two sub components. The first is the lithium flow passage that is comprised of two concentric cylinders that run the length of the inner Inconel heat pipe. At both ends of the concentric cylinders are donut shaped passages for the inlet and exit of the lithium. Thirty, equally spaced holes are made in the "donuts" at both ends to allow the lithium to enter and exit the concentric cylindrical lithium flow passages. This outer double shell is slip fit over the Inconel inner tube. Inconel's coefficient of thermal expansion is much greater than that of Niobium and the two surfaces are in intimate contact when the system is brought up to operating temperature. Because lithium has a high affinity for oxygen and $\mathrm{Nb}-1 \% \mathrm{Zr}$ is virtually transparent to the oxygen in the zirconia a method to slow the diffusion of oxygen through the $\mathrm{Nb}-1 \% \mathrm{Zr}$ is needed. Molybdenum has been shown to slow the diffusion of oxygen and is used in the multicouple thermoelectrics on the SP-100 power system. A thin layer of molybdenum is Hot Isostatically Pressed (HIPed) to the $\mathrm{Nb}-1 \% \mathrm{Zr}$ inner tube to slow this diffusion process.

The need for the insulating layer of zirconia resulted from the maximum heat flux constraint of $40 \mathrm{~W} / \mathrm{cm}^{2}$. To achieve the desired temperature drop of $75 \mathrm{~K}$ across the five series heat pipes it is necessary to have a minimum lithium inlet temperature of $1141 \mathrm{~K}(1066 \mathrm{~K}+75 \mathrm{~K})$. With only the Inconel and $\mathrm{Nb}-1 \% \mathrm{Zr}$ layers present, the resulting heat flux into the first evaporator would be $130 \mathrm{~W} / \mathrm{cm}^{2}$. Therefore, an insulating layer is needed to control the maximum heat flux into the evaporator. Since the lithium temperature entering each of the five series heat pipes is different (e.g., there is a $15 \mathrm{~K}$ temperature drop through each heat pipe) it is necessary to determine the zirconia thickness for each heat pipe that would result in the design goal of $35 \mathrm{~W} / \mathrm{cm}^{2}$ maximum heat flux.

\section{Thermal Analusis}

A computer model of a 5 degree section of the heat exchanger wall was constructed and used to perform the thermal analysis. PATRAN was used to generate the geometry and calculate the thermal resistance's between thermal nodes. SINDA is used to solve for the steady state temperature solution. The lithium outlet temperature is calculated by the computer model, and the length of the heat pipe is varied until the lithium temperature drop through the heat pipe equaled $15 \mathrm{~K}$ (corresponding to $10 \mathrm{~kW}$ power input to each heat pipe). The computer model is run iteratively to determine the zirconia thicknesses, lithium temperature and heat pipe length that would result in a heat flux of $35 \mathrm{~W} / \mathrm{cm}^{2}$ at the entrance to each heat pipe and give the desired total heat input of $10 \mathrm{~kW}$ into each of the five series evaporators. A limit of $35 \mathrm{~W} / \mathrm{cm}^{2}$ was used because of the maximum tolerances achievable in the 
spray coating of the zirconia. This limit can significantly alter the heat flux into the evaporator. A zirconia thickness of $2.03 \times 10^{-4}$ meters is used on the last of the five heat pipes as a minimum practical application thickness. The zirconia thickness for each of the four upstream heat pipes was then determined in sequence, using a lithium inlet temperature $15 \mathrm{~K}$ higher than that for the downstream neighbor.

The main uncertainty in the analysis is the degree of thermal contact at the zirconia/molybdenum interface. This uncertainty was handled in the analysis by bracketing the thermal contact resistance between a conservative stainless steel/niobium interface value and no contact resistance.

\section{Stress Analysis}

This modeling and static analysis is done using PATRAN. The casing shell which is 0.3175 meter diameter and $8.9 \times 10^{-4}$ meters thick is attached to the ribs. There are two end ribs and a center rib which are used to mount the casing shell to the Stirling convertor. These ribs are $2.54 \times 10^{-2}$ meters deep radially and are an integral part of the convertor housing. The center rib is $3.2 \times 10^{-3}$ meters thick while the end ribs are $4.7 \times 10^{-3}$ meters thick. The center rib reduces the effective pumping height of the fluid which increases the heat pipe pumping margin. There are ten heat pipes located in two circumferential rows, equally spaced and staggered as shown in the figures. The heat pipes extensions are $8.89 \times 10^{-2}$ meters in diameter, 0.13208 meters high from the casing shell and $8.9 \times 10^{-4}$ meters thick. The heat pipes are fitted with a heat source sleeve that has an initial diametral clearance of $3.5 \times 10^{-4}$ meters between the heat pipe and the sleeve. This analysis reflects the state of stress with this initial clearance closed and an additional interference fit of $1.25 \times 10^{-4}$ meters between the Niobium sleeve and Inconel evaporator at operating temperatures. The heat pipe, casing shell, and ribs are made of Inconel 617. The casing shell, heat pipes, and ribs are modeled using QUAD elements. The loads are due to the $7.2720 \times 10^{4}$ Pascal's internal sodium heat pipe operating pressure and the thermal coefficient of expansion mismatch between the Inconel and the niobium. The actual temperature of the heat pipe and the sleeve is $1066 \mathrm{~K}$ and $1150 \mathrm{~K}$ respectively.. The temperature stresses are due to any restrained thermal growth occurring after the clearance between the sleeve and the heat pipe is closed. The sleeve and heat pipe were modeled as if there is no clearance between them at a datum temperature that has no stress effect. To effect an interference fit of $1.262 \times 10^{-5}$ meters, the calculated required rise is temperature is $435 \mathrm{~K}$. Because the temperature causes the entire convertor to expand uniformly it is fair to assume that the ribs are free to translate radially under the effect of temperature. For the pressure load, however, the housing, which is relatively stiff, may not expand proportionately. It may be fair, however to assume that the rib ends do not translate radially. Such situations offer difficulty in modeling the boundary conditions for the combined pressure and temperature load conditions. Since the thermal condition will have larger expansion than the pressure condition, the boundary conditions used were from thermal considerations. However a comparison of stresses due to this variation of boundary conditions were made. Table 2 shows a mass breakdown of the system.

Table 2.

Weight Comparisons (Weight (kg) / Thickness (Meters))

\begin{tabular}{|c|c|c|c|c|c|}
\hline \multirow{3}{*}{$\begin{array}{c}\text { Conductively } \\
\text { Coupled Heat } \\
\text { Exchanger }\end{array}$} & $\begin{array}{c}\text { Torus/Heat } \\
\text { Pipe }\end{array}$ & Radiator Fins & Insulation & Manifolds & Total \\
\hline & 7.4 & 7.27 & 8.18 & 1.5 & 24 \\
\hline & 8.9E-04 & $1.27 E-03$ & $5.08 E-04$ & 8.9E-04 & \\
\hline
\end{tabular}

Comparison of the effect of the displacement boundary condition at the inner edges of the ribs showed a maximum stress of $3.8054 \times 10^{7}$ Pascal's. These stresses are at the shell to heat tube junction. It is possible that the shell or a portion of the heat tube can be thickened to reduce the stress at this junction. Such optimizations can be performed before finalizing the design. Analysis shows the stress values due to the temperature in the Niobium sleeve portion was $1.404 \times 10^{8}$ Pascal's. Combined loads of pressure and temperature are $1.405 \times 10^{8}$ Pascal's in the Niobium sleeve and $1.557 \times 10^{7}$ Pascal's in the Inconel 617 heat tube. The allowable stress for Inconel 617 is $6.204 \times 10^{8}$ Pascal's at $1066 \mathrm{~K}$ temperature for a fatigue life of 60,000 hours. For Niobium the stress for $1 \%$ creep in 100,000 hours is $1.350 \times 10^{7}$ Pascal's at $1350 \mathrm{~K}$. 


\section{Multi-Foil Insulation}

Prior to determining the zirconia thickness for each heat pipe it was necessary to determine the heat loss that could be expected through the Multi-Foil insulation. This was necessary since the heat loss would affect the required lithium temperature. This heat loss was calculated over the outer surface area of each heat pipe and compared to the desired heat load into the evaporator.

\section{Elow Channel Sizing}

Pressure drop calculations were performed to size the Niobium tubing diameter and wall thickness to match the primary loop SP-100 characteristics. The wall thickness was set by manufacturing considerations rather than the internal pressure of $1.516 \times 10^{5}$ Pascal's in the SP-100 lithium loop. To insert the heat exchanger directly into the SP-100 loop required a pressure drop of $2.689 \times 10^{4}$ Pascal's . Calculations were made using equivalent hydraulic diameters and used to get initial estimates on pressure drops throughout the heat exchanger. A total pressure drop of $2.716 \times 10^{4}$ Pascal's was found for the drops through the heat exchanger. The majority (over $1 / 2$ ) of the pressure drop occurs at the 30 hole inlet to each of the heat pipe tubes. To reduce this pressure drop the lithium inlet tube position on each of the heat pipes can be changed. This will be reflected in future design work.

\section{Heat Pine}

An analysis was performed to determine the wicking, artery, and flow channel sizes need to transfer the sodium from the condenser section of the Starfish to the evaporator surfaces and back to the condenser of the heat exchanger. One hundred mesh screen was chosen as the wick size of choice in this heat exchanger. Tests in a simulated 1/10 segment Starfish heat pipe for the CTPC has demonstrated performance to heat fluxes through the evaporator wicking in excess of $21 \mathrm{~W} / \mathrm{cm}^{2}$. Experience of respected heat pipe vendors suggests that this could be extended to over $40 \mathrm{~W} / \mathrm{cm}^{2}$. This value was used in all of the designs. Computations of the boiling limit with 100 mesh screen verify this limit, albeit by theory that is not supported by much experimental data. At the same time, other computations show that the capillary pumping limit of two layers of 100 mesh screen is not reached. This is true even in ground testing where hydrostatic forces impose a penalty. Moreover, the screen should fill the wick full of fluid in the evaporator before evaporation causes liquid flow to commence. Additional computations showed that three layers of 140 mesh screen would be equally satisfactory, and perhaps better, with respect to the boiling and capillary pumping limits. However, until more is known about the corrosion life of high nickel alloys a wicking choice involving coarser screening is desirable, and dictates 100 mesh screen as the front runner in this design.

In the meantime, it must be noted that the arteries of the present design use screen much finer than that in the wicking. This was to avoid the penetration of the artery wall by sodium vapor, which would cause artery malfunction. The resolution of this contradiction (wicking mesh versus artery mesh) depends upon a technology effort that is currently underway. This involves the complete coating of all surfaces of the high nickel alloy by a thin corrosion-resistant material currently being studied. Should this technique be successful, it is quite likely that updates of the present design would be able to use finer screen. Also, because of the very low artery pressure drops, it may be possible to make the larger artery diameters less.

\section{CONCLUSIONS}

Two types of heat exchangers which would couple the primary loop of the SP-100 and the heater head of the SSPC were explored. Masses for the radiatively coupled designs varied from $41 \mathrm{~kg}$ to $176 \mathrm{~kg}$. Of the radiatively coupled concepts a single torus design was selected based on fabrication and assembly issues along with a mass analysis. The mass for this design is $42 \mathrm{~kg}$ or $1.64 \mathrm{~kg} / \mathrm{kWe}$. A single design was explored for the conductively coupled concept. Significantly greater detail in the analysis was performed on this design and leads to a higher degree of accuracy in the mass estimated and design configuration. The conductively coupled concept weighed 18 $\mathrm{kg}$ or $0.73 \mathrm{~kg} / \mathrm{kWe}$.

The direct conduction concepts provide lighter weight systems because of the ability to run the Starfish evaporator at higher heat fluxes than those permitted by the radiatively coupled systems. The primary advantages of the radiatively coupled designs were the minimal material interface problems. The conductively coupled concepts, besides the reduction in mass, provide a relatively small volume along with an easier assembly process (especially in 
wicking of the heat pipe). Their disadvantages are tight tolerances and material joining problems associated with the refractory to superalloy interface.

\section{Acknowledgments}

This work was performed with funding from the Civil Space Technology Initiative at NASA Lewis Research Center during the summer and fall of 1992.

\section{References}

B. Banks, S.. Rutledge, M. Mirtich, T. Behrend, D. Hotes, M. Kussmaul, J. Barry, C. Stidham, T. Stueber, F. DiFilippo(1988) “Arc-Textured Metal Surface for High Thermal Emittance Space Radiators," NASA TM 10894, 1988.

J. Dudenhoefer, J. Winter (1992) “Progress Update of NASA's Free-Piston Stirling Space Power Converter Technology Project," Nuclear Technologies for Space Exploration Conference, Jackson Hole, Wyoming.

Lubarsky, B., and S. J. Kaufman (1955) "Review of Experimental Investigations of Liquid Metal Heat Transfer," NACA Tech Note 3336, Washington D.C., .

Tranter Inc.(1990) "PLATECOIL, The Most Versatile and Efficient Prime Surface Heat Exchanger" Tranter, Inc., Texas Division, Wichita Falls, TX,

Wortham, D. W. (1976) "Application of Multi-Foil Insulation to the Brayton Isotope Power System and Conceptual Design of Multi-Foil Insulation for the Flight System", Thermo Electron Corporation Report No. TE4209-100-76, June 11, 1976.

\section{DISCLAIMER}

This report was prepared as an account of work sponsored by an agency of the United States Government. Neither the United States Government nor any agency thereof, nor any of their employees, makes any warranty, express or implied, or assumes any legal liability or responsibility for the accuracy, completeness, or usefulness of any information, apparatus, product, or process disclosed, or represents that its use would not infringe privately owned rights. Reference herein to any specific commercial product, process, or service by trade name, trademark, manufacturer, or otherwise does not necessarily constitute or imply its endorsement, recommendation, or favoring by the United States Government or any agency thereof. The views and opinions of authors expressed herein do not necessarily state or reflect those of the United States Government or any agency thereof. 
Public reporting burden for this collection of information is estimated to average 1 hour per response, including the time for reviewing instructions, searching existing data sources, gathering and maintaining the data needed, and completing and reviewing the collection of information. Send comments regarding this burden estımate or any other aspect of this collection of information, including suggestions for reducing this burden, to Washington Headquarters Services, Directorate for Information Operations and Reports, 1215 Jefferson Davis Highway, Suite 1204, Arlington, VA 22202-4302, and to the Office of Managernent and Budget, Paperwork Reduction Project (0704-0188), Wastungton, DC 20503.
1. AGENCY USE ONLY (Leave blank)
2. REPORT DATE
3. REPORT TYPE AND DATES COVERED
December 1993
Technical Memorandum

\section{TITLE AND SUBTITLE}

Preliminary SP-100/Stirling Heat Exchanger Designs

6. AUTHOR(S)

Paul Schmitz, Leonard Tower, Ronald Dawson, Brian Blue and Pat Dunn

\section{FUNDING NUMBERS}

WU-583-02-21

\section{PERFORMING ORGANIZATION NAME(S) AND ADDRESS(ES)}

National Aeronautics and Space Administration

Lewis Research Center

Cleveland, Ohio 44135-3191

9. SPONSORING/MONITORING AGENCY NAME(S) AND ADDRESS(ES)

National Aeronautics and Space Administration

Washington, D.C. 20546-0001
8. PERFORMING ORGANIZATION REPORT NUMBER

E-8288

10. SPONSORINGMONITORING AGENCY REPORT NUMBER

NASA TM-106444

11. SUPPLEMENTARY NOTES

Prepared for the Eleventh Symposium on Space Nuclear Power and Propulsion, cosponsored by the Institute for Space Nuclear Studies and Amencan Nuclear Society, Albuquerque, New Mexico, January 10-14, 1994. Paul Schmitz and Leonard Tower, Sverdrup Technology, Inc., Lew1s Research Center Group, 2001 Aerospace Parkway, Brook Park, Ohio 44142 (work funded by Contract NAS3-25266); Ronald Dawson, Aerospace Design and Fabrication Inc. 3003 Aerospace Parkway, Brook Park, Oho, 44142; Brian Blue and Pat Dunn, NASA Lewis Research Center. Responsible person, Paul Schmitz, (216) $433-6174$.

12a. DISTRIBUTION/AVAILABILITY STATEMENT

12b. DISTRIBUTION CODE

Unclassified - Unlimited

Subject Category 20

13. ABSTRACT (Maximum 200 words)

Analytic modeling of several heat exchanger concepts to couple the SP-100 nuclear reactor primary lithium loop and the Space Stirling Power Convertor (SSPC) was performed. Four $25 \mathrm{kWe}$ SSPC's are used to produce the required $100 \mathrm{~kW}$ of electrical power. This design work focused on the interface between a single SSPC and the primary lithium loop. Manifolding to separate and collect the four channel flow was not modeled. This work modeled two separate types of heat exchanger interfaces (conductive coupling and radiative coupling) to explore their relative advantages and disadvantages. The minimum mass design of the conductively coupled concepts was $18 \mathrm{~kg}$ or $0.73 \mathrm{~kg} / \mathrm{kWe}$ for a single $25 \mathrm{kWe}$ convertor. The minimum mass radiatively coupled concept was $41 \mathrm{~kg}$ or $1.64 \mathrm{~kg} / \mathrm{kWe}$. The direct conduction heat exchanger provides a lighter weight system because of its ability to operate the Stirling convertor evaporator at higher heat fluxes than those attainable by the radiatively coupled systems. Additionally the conductively coupled concepts had relatively small volumes and provide potentially simpler assembly. Their disadvantages were the tight tolerances and material joing problems associated with this refractory to superalloy interface. The advantages of the radiatively coupled designs were the minimal material interface problems.

14. SUBJECT TERMS 15. NUMBER OF PAGES

SP-100; Nuclear; Stirling; Space; Power

11

16. PRICE CODE

A03

\begin{tabular}{|c|c|}
\hline $\begin{array}{c}\text { 17. SECURITY CLASSIFICATION } \\
\text { OF REPORT } \\
\text { Unclassified }\end{array}$ & $\begin{array}{c}\text { 18. SECURITY CLASSIFICATION } \\
\text { OF THIS PAGE } \\
\text { Unclassified }\end{array}$ \\
\hline
\end{tabular}

19. SECURITY CLASSIFICATION OF ABSTRACT Unclassified 
National Aeronautics and

Space Administration

Lewis Research Center

21000 Brookpark Rd.

Cleveland, $\mathrm{OH}$ 44135-3191

Official Business

Penalty for Private Use $\$ 300$

POSTMASTER: If Undeliverable - Do Not Return 